\title{
A Needle in the Fetal Brain: The Rare Role of Transabdominal Cephalocentesis in Fetal Hydrocephalus
}

\author{
P Swetha ${ }^{1}$, Shobha Dhananjaya ${ }^{1}$, Amogh Ananda Rao ${ }^{2}$, Ashutosh Suresh ${ }^{2}$, Chiranth Nadig ${ }^{1}$ \\ 1. Obstetrics and Gynaecology, Jagadguru Jayadeva Murugarajendra Medical College, Davangere, IND 2. Internal \\ Medicine, Jagadguru Jayadeva Murugarajendra Medical College, Davangere, IND
}

Corresponding author: Amogh Ananda Rao, amoghanand7596@gmail.com

\begin{abstract}
Fetal hydrocephalus is a fairly common occurrence in pregnant women, surfacing early or late in the pregnancy. The perinatal and pediatric outcomes are largely determined by the cause of hydrocephalus and the extent of the irreversible destruction of the brain tissue. In pregnancies where the fetal prognosis is unfavorable, aspirating the cerebrospinal fluid (CSF) to facilitate vaginal delivery is an option.
\end{abstract}

In this report, we present the case of a primigravida with term fetal hydrocephalus who underwent ultrasound-guided transabdominal cephalocentesis and subsequently delivered vaginally without any adverse perinatal outcomes.

Categories: Obstetrics/Gynecology, Pediatrics, Pediatric Surgery

Keywords: fetal hydrocephalus, transabdominal cephalocentesis

\section{Introduction}

Fetal hydrocephalus is not uncommon in the practice of obstetrics, with an incidence of around 0.2-1 per 1,000 live births [1]. Hydrocephalus can be broadly classified into two types based on its etiology: congenital and acquired. Generally, developmental malformations like the Arnold-Chiari and Dandy-Walker malformations, megalencephaly syndromes, and the VACTERL-H spectrum are associated with congenital hydrocephalus. Infections and hemorrhage represent the other etiological factors causing hydrocephalus [2]. Its pathobiology usually involves the obstruction of the ventricular system, most frequently occurring at the aqueduct of Sylvius. The perinatal and pediatric outcomes are largely determined by the cause of hydrocephalus and the extent of the irreversible destruction of the brain tissue. In pregnancies where the fetal prognosis is unfavorable, aspirating the cerebrospinal fluid (CSF) to facilitate vaginal delivery is an option. Cephalocentesis is a procedure to drain the excess CSF from the fetus. It is commonly performed vaginally or through the abdomen with ultrasonographical guidance. This method averts the morbidity that ensues obstructed labor, and a cesarean section, especially in primigravida.

Review began 03/07/2021 Review ended 03/31/2021 Published 04/07/2021

\section{(๑) Copyright 2021}

Swetha et al. This is an open access article distributed under the terms of the Creative Commons Attribution License CC-BY 4.0., which permits unrestricted use, distribution, and reproduction in any medium, provided the original author and source are credited.
We discuss the case of a primigravida with term fetal hydrocephalus who underwent ultrasound-guided transabdominal cephalocentesis and subsequently delivered vaginally without any adverse perinatal outcomes.

\section{Case Presentation}

A 19-year-old primigravida with 37 completed weeks of gestation was referred to our center in September 2020 due to fetal hydrocephalus for further management. Her term scan had revealed a single, live, intrauterine pregnancy of around 36 weeks' gestation in the longitudinal lie, with gross hydrocephalus. The placenta was located in the fundal left-lateral region. She had no comorbid conditions during the antenatal period and had followed up regularly with the obstetrician.

Three ultrasound scans were done during the 14th, 17th, and 21st weeks of gestation; all the scans were unremarkable (Figure 1). On detailed ultrasonographic examination at 37 weeks of gestation, we found an enlarged fetal cerebral ventricular system suggestive of hydrocephalus (biparietal diameter: $122 \mathrm{~mm}$ ), basal cisterna obstruction, and reduced brain mantle thickness $(8.4 \mathrm{~mm})$. The estimated fetal weight was 2,500 grams. No calcifications or space-occupying lesions were noticed. No features indicative of Dandy-Walker and Arnold Chiari malformations, or non-pressure hydrocephalus were noticed. However, we observed polyhydramnios and asymmetrical growth restriction.

Infectious etiology of hydrocephalus was ruled out on obtaining negative results for TORCH panel, HIV, hepatitis B, tuberculosis, and also coronavirus. The neonatologist opined that the prognosis of the baby is guarded due to cerebral atrophy. 


\section{Cureus}

\section{TIMELINE OF EVENTS}

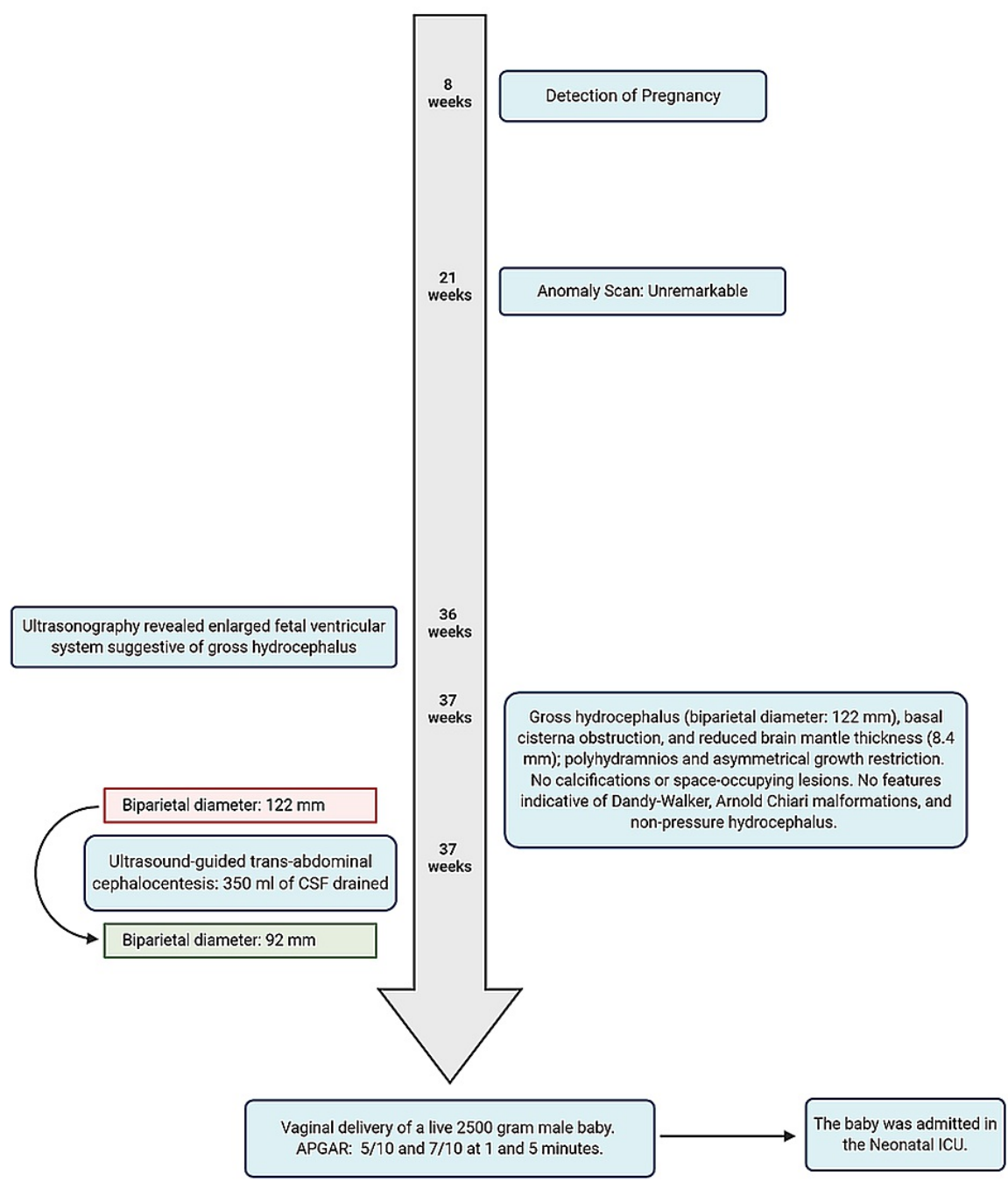

\section{FIGURE 1: Timeline of events}

CSF: cerebrospinal fluid; ICU: intensive care unit; APGAR: Appearance, Pulse, Grimace, Activity, and Respiration

After counseling the parents regarding the poor perinatal outcome and the plausible risks of a

ventriculoperitoneal shunt procedure following cesarean delivery, the mother opted for a vaginal delivery. Therefore, we planned the vaginal delivery at 37 weeks of gestation to avoid the potential maternal morbidity associated with a primary cesarean section besides affirming the mother's wish. The patient had neither set into spontaneous labor nor was the fetal head engaged. Consequently, we counseled the patient for ultrasound-guided transabdominal cephalocentesis, and she consented to it despite its invasive nature.

Local anesthesia was administered under aseptic precautions. The posterior fontanelle was located using transabdominal ultrasonography. An 18-gauge spinal needle was inserted through the posterior fontanelle and aspirated to ensure the free flow of clear fluid. Around 350 milliliters of CSF was drained. The biparietal diameter reduced significantly from $122 \mathrm{~mm}$ before the procedure to $92 \mathrm{~mm}$ after draining the CSF (Figures 2, 3). 


\section{Cureus}

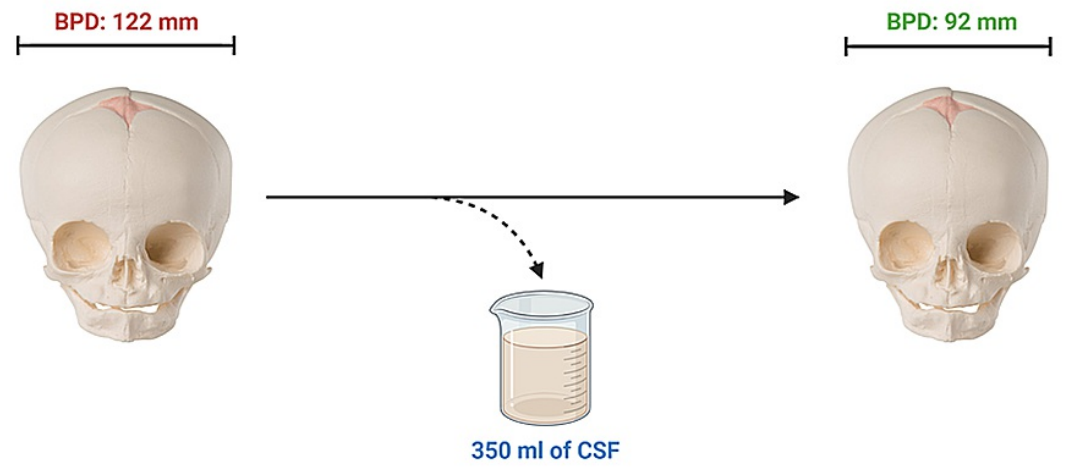

Ultrasound-guided trans-abdominal cephalocentesis was performed to drain around 350 milliliters of cerebrospinal fluid (CSF), thereby reducing the biparietal diameter (BPD) from 122 millimeters to 92 millimeters, facilitating vaginal delivery.

\section{FIGURE 2: Representative illustration of the reduction in biparietal diameter}

BPD: biparietal diameter; CSF: cerebrospinal fluid

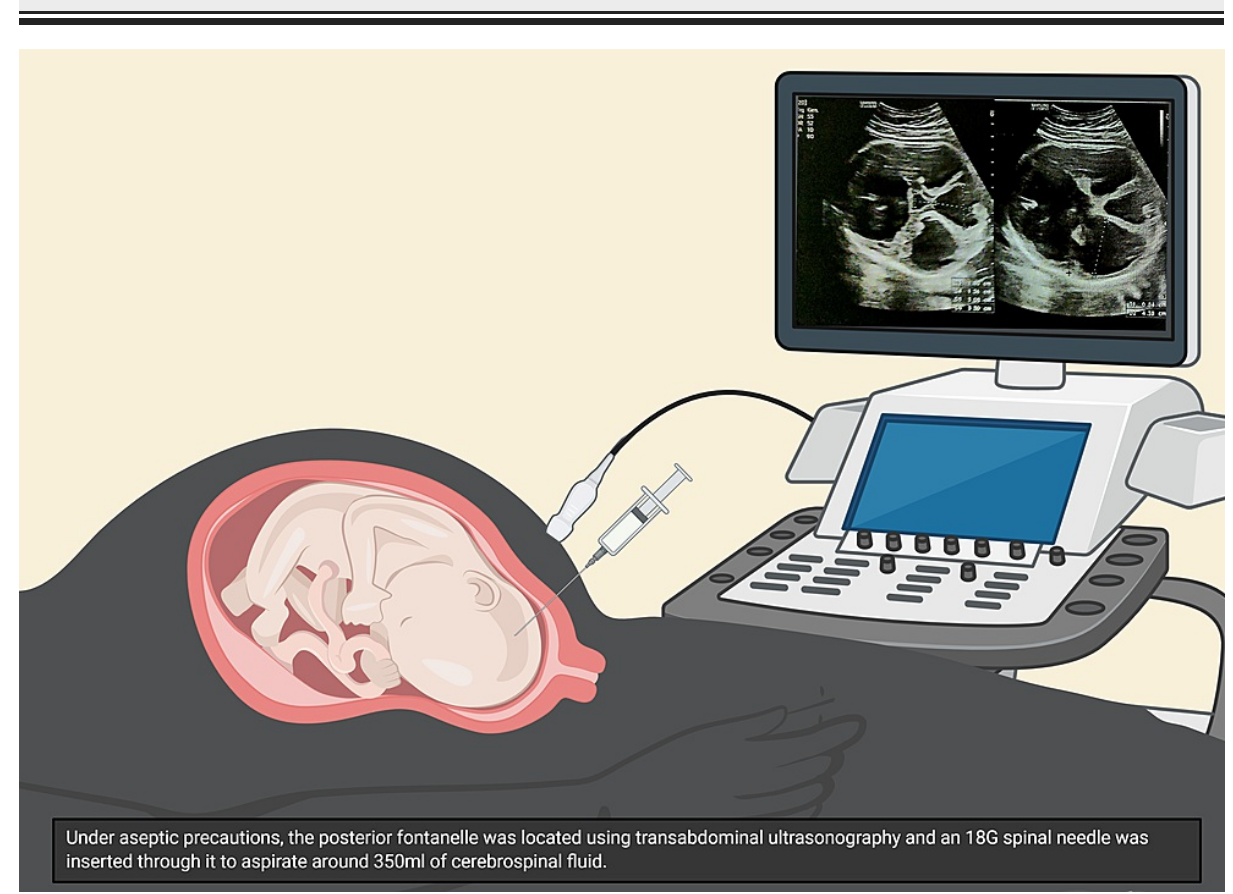

\section{FIGURE 3: Representative illustration of the procedure}

The patient was induced with a single dose of 25-mcg oral misoprostol and further augmented with intravenous low-dose oxytocin titration. The first and second stages of labor progressed satisfactorily and she delivered a live 2,500-gram male baby vaginally. The baby cried immediately after birth and had an Appearance, Pulse, Grimace, Activity, and Respiration (APGAR) score of 5/10 and 7/10 at one and five minutes, respectively. The baby was admitted to the neonatal ICU for three days, but the parents were unwilling to have the child undergo further medical intervention, for the prognosis was guarded. The baby expired two months after birth due to intractable seizures. A fetal autopsy could not be performed as the parents did not give consent to it.

\section{Discussion}

Hydrocephalus, the enlargement of the fetal ventricular system, is associated with a repertoire of conditions. Antenatally, on ultrasonography, a separation of more than $33 \mathrm{~mm}$ between the ventricular margin and the choroid plexus is considered abnormal; macrocephaly is an occasional finding. As a result of the increased 
intracranial pressure, there is usually a variable degree of parenchymal thinning [3]. The overall incidence of fetal hydrocephalus is around $0.2-1$ per 1,000 live births [1].

Factors such as the gestational age at the time of diagnosis, fetal viability, and the association with other malformations primarily dictate the obstetric management of hydrocephalus. Besides an eventual cesarean section, management options include the placement of a ventricular-amniotic shunt or cephalocentesis [4]. Decompression of the fetal skull can be performed either transabdominally under ultrasound guidance or transvaginally. Since the transabdominal route is more invasive and painful, the latter is preferred due to its psychological advantage [5].

Chasen et al. have reported in their study that perinatal death occurred in 10 of the 11 cases where cephalocentesis was performed [6]. In an analysis of 87 fetal hydrocephalus cases, Garne et al. reported that $53 \%$ of the fetuses were still-born or were terminated [7]. However, intractable seizures and global developmental delay with brainstem dysfunction occurred in the majority of survivors [6]. Ventricular-amniotic shunting, when performed in cases of obstructive hydrocephalus, was associated with severe neurological morbidity and procedure-related fetal mortality [8].

Although transabdominal cephalocentesis is a destructive procedure, the physician's beneficence-based obligation to the mother in avoiding a cesarean section must be considered in these cases.

\section{Conclusions}

Even though cephalocentesis is a destructive procedure and not in routine use, it still has a pertinent role in modern obstetrics practice. Cephalocentesis is a worthy alternative to a cesarean section in circumstances where the fetus is nonviable or has a rather dismal prognosis after birth.

\section{Additional Information \\ Disclosures}

Human subjects: Consent was obtained or waived by all participants in this study. Conflicts of interest: In compliance with the ICMJE uniform disclosure form, all authors declare the following: Payment/services info: All authors have declared that no financial support was received from any organization for the submitted work. Financial relationships: All authors have declared that they have no financial relationships at present or within the previous three years with any organizations that might have an interest in the submitted work. Other relationships: All authors have declared that there are no other relationships or activities that could appear to have influenced the submitted work.

\section{References}

1. Cavalheiro S, Moron AF, Almodin CG, Suriano IC, Hisaba V, Dastoli P, Barbosa MM: Fetal hydrocephalus. Childs Nerv Syst. 2011, 27:1575-83. 10.1007/s00381-011-1539-1

2. Tully HM, Dobyns WB: Infantile hydrocephalus: a review of epidemiology, classification and causes. Eur J Med Genet. 2014, 57:359-68. 10.1016/j.ejmg.2014.06.002

3. Weerakkody Y, El-Feky M: Fetal hydrocephalus. Radiopaedia [online only]. 2021,

4. Chervenak FA, Berkowitz RL, Tortora M, Hobbins JC: The management of fetal hydrocephalus . Am J Obstet Gynecol. 1985, 151:933-42. 10.1016/0002-9378(85)90672-6

5. Chanrachakul B, Chittachareon A, Herabutya Y: Cephalocentesis with the modified Smellie's perforator . Int J Gynaecol Obstet. 2002, 76:203-6. 10.1016/80020-7292(01)00561-6

6. Chasen ST, Chervenak FA, McCullough LB: The role of cephalocentesis in modern obstetrics . Am J Obstet Gynecol. 2001, 185:734-6. 10.1067/mob.2001.117487

7. Garne E, Loane M, Addor MC, Boyd PA, Barisic I, Dolk H: Congenital hydrocephalus--prevalence, prenatal diagnosis and outcome of pregnancy in four European regions. Eur J Paediatr Neurol. 2010, 14:150-5. 10.1016/i.ejpn.2009.03.005

8. Pillarisetty LS, Rich G, Mannem M, Tsen A: Intrapartum cephalocentesis: case report and review. Gynecol Obstet. 2019, 9:4. 10.4172/2161-0932.1000502 